\title{
INNOVATIVE CIRCULAR SOLUTIONS AND SERVICES FOR NEW BUILDINGS AND REFURBISHMENTS
}

\author{
GAETANO BERTINO, FRANCESCO MENCONI, ANDREA ZRAUNIG, \\ EDUARDO TERZIDIS \& JOHANNES KISSER \\ Alchemia-nova GmbH, Austria
}

\begin{abstract}
The housing sector is responsible for more than $50 \%$ of global resource extraction, about $50 \%$ of world energy consumption, $1 / 3$ of water consumption and furthermore generates about $1 / 3$ of all produced waste. A new, circular approach is needed to enable better decision-making on the selection of innovative architectural solutions for all phases of a building's life cycle. The current building sector's business model must be redesigned to include the application of new and improved methods, solutions and innovative services, and advance a positive transition from a linear economy to a circular economy. We will present the circular interventions carried out on a centenary building located in Vienna in the framework of the HOUSEFUL project. HOUSEFUL is an EU-funded initiative with the objective to develop and demonstrate integrated circular services, focusing on the optimal management of resources throughout the life cycle of new or existing buildings. The demonstration will include technologies to circulate all process flows while reducing the overall energy demand. These technologies will be offered as integrated services to produce treated rain and wastewater for internal reuse, the generation of renewable energy from biogas, compost production combined with urban gardening and for the use of nutrients in a greenhouse. The design of more efficient processes, such as green walls, innovative conservatories, building-integrated solar thermal and photovoltaic panels will improve building energy efficiency. All process flows will be intensely monitored to ensure safety and collect data for further replication cases. The solutions will also include the use of sustainable and upcycled materials and the implementation will be based on the principles of reversibility and de-constructability. The final services of the building will be elaborated in co-creation workshops with a multitude of stakeholders. Additional service-oriented modelling facilitates replication for the transition to the circular housing sector.
\end{abstract}

Keywords: circular economy, service-driven business models, nature-based solutions, innovative use of secondary resources, technological innovation, resource and energy efficiency.

\section{INTRODUCTION}

The transition from a linear to a circular business economy is being implemented at an industrial scale in Europe. Many referenced case studies and innovative projects are focused on the innovative design of products, smart production lines in industry and energy efficient processes. However, this transition has not yet taken place at all levels of the housing sector (energy, water, waste and materials). Most of the time the circularity only focuses on one of these levels. For that reason, a new circular thinking approach is required to enable better decision-making on the selection of circular solutions at the different, or various levels for all the different stages of a building's life cycle to attain optimal building functionality and maximise the reuse of resources in a co-creation process [1].

Meeting the challenges outlined in Fig. 1 requires the redesign of current housing business model, creating new methods for the evaluation of the circularity level in the housing sector while co-creating new solutions and services for its improvement. The transition from a linear to a circular business model in this sector will contribute massively to establishing a lowcarbon urban economy in future "green" cities, and the reduction of waste and GHG emissions, recognising the COP21 objectives and the goals proposed by the 2030 Agenda for Sustainable Development (United Nations, 2015). 


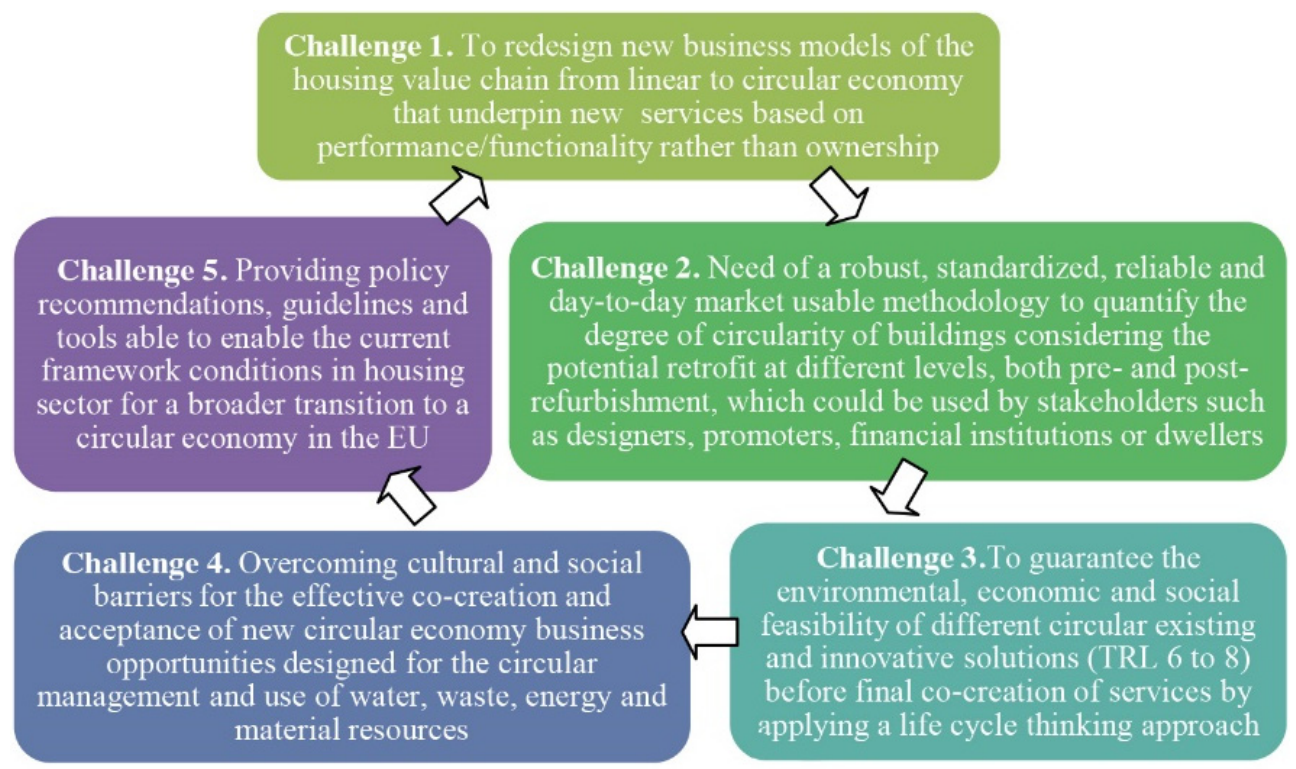

Figure 1: Main HOUSEFUL challenges addressed for a circular housing sector.

The main goal of the HOUSEFUL project is to develop and demonstrate an integrated systemic "service" composed of different circular technical solutions in the current housing value chain. The HOUSEFUL service will aim at the circular management and efficient use of water, waste, energy and material resources for all the stages of European building's life cycle and will be presented as an on-line "Software as a Service (SaaS)", enabling the replication of proposed circular solutions at EU level: renting, leasing, customer service, capacity building service, and various combination thereof. The integrated HOUSEFUL service and proposed technical solutions will be demonstrated at a large scale in four representative European residential buildings (frontrunner buildings) characterised by variations in climate, social and legislative/organisational conditions, as follows: "DEMO 1" in Sabadell, Spain - a building constructed in the 1960s to be refurbished for social housing; "DEMO 2" in Terrassa, Spain - a to-be refurbished social housing estate built in the 1970s; "DEMO 3" in Vienna, Austria - a centenary building designated for both private and commercial use; "DEMO 4" in Vienna, Austria - a new social housing building constructed in 2017.

The buildings were selected with regard to their spatial and geographical distribution which would guarantee the collection of data on the feasibility and replication of solutions across differences in social, cultural and current practices on housing, differences in national regulation regarding construction and refurbishment, and common European building archetypes. Further considerations related to variations in scale and number of dwellers per building, climate-oriented differences in characteristic and typologies of residential buildings, and common challenges shared by construction companies, related professionals and regional/national housing agencies. The frontrunners will accordingly act as references for replication activities of proposed solutions with a further ten so-called "Follower" buildings to be identified during the first year of the project execution. 


\section{VIENNA CENTENARY FRONTRUNNER BUILDING}

DEMO 3 is a privately-owned residential building which includes an office, laboratory storage-basement, garden and residential space. This building reflects a typical building category of Central European centenary buildings that were not destroyed during the war and it is due for substantial refurbishment. Main demo objectives are to demonstrate the feasibility of HOUSEFUL services offered to the users (and possibly the neighbours) of the building, while at the same time reducing the energy demand and closing water and nutrient cycles by recovering water and nutrients from wastewater and organic waste. This will be achieved by structural modifications with regard to pipe installations, roof structure, facade change, integration of winter gardens, and garden infrastructure. Main HOUSEFUL solutions will also involve the use of circular materials to almost passive house standards but including new functionalities on facades and the roof such as nature-based solutions for wastewater treatment. Post renovation energy requirements will be catered for by photovoltaics and the incineration of biogas produced directly in the building. All the organic waste materials that are produced in the building will be used for biogas generation and in-vessel composting. Wastewater will be treated in plant-based water filtration and purification systems allowing for the dissolved nutrients used as fertigation in urban farming applications, perhaps even in a greenhouse structure.

\subsection{Technical solutions}

In detail, the technical solutions can be grouped according to the resource considered, accordingly: materials, water, waste and energy vectors.

Additionally, the integration of all the solutions must be considered for the realization of control, analysis and management services. Fig. 3 above shows the main water, bio-waste

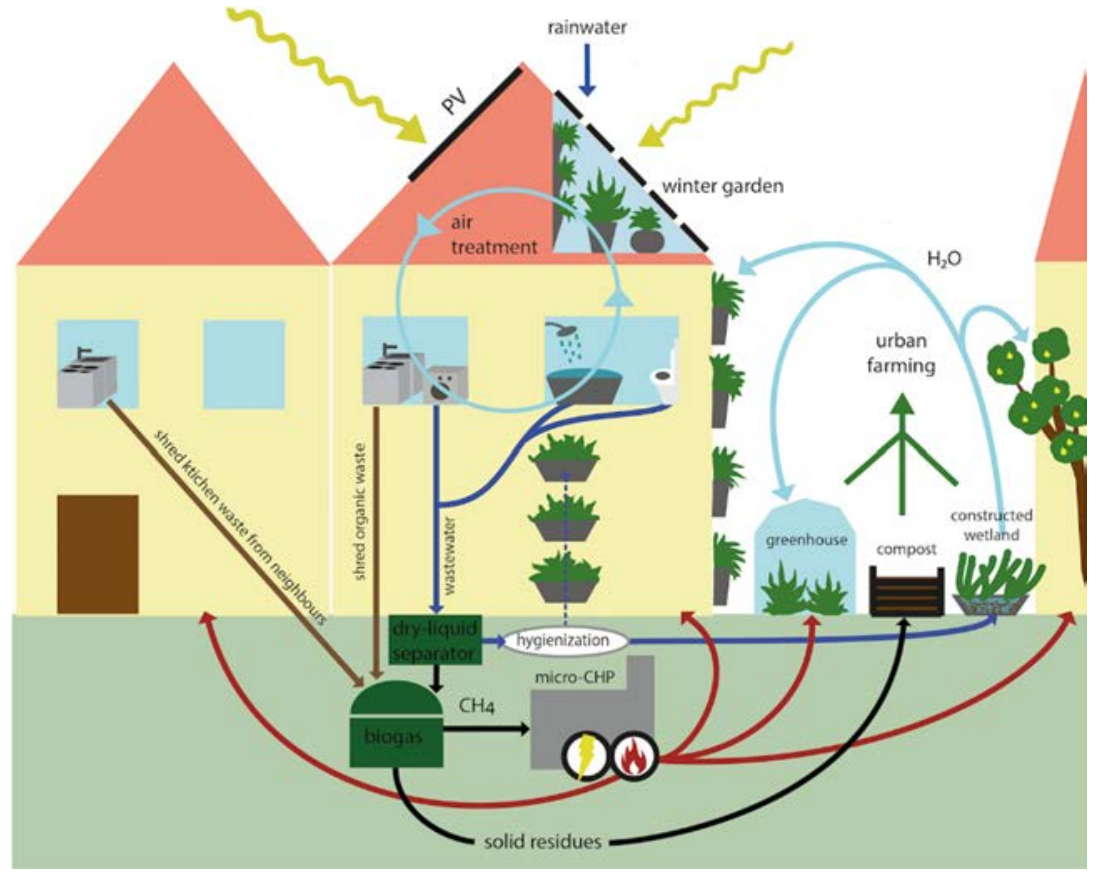

Figure 2: Main water/waste/energy flows HOUSEFUL solutions. 
and energy flows foreseen within a building, together with a representation of the technology behind the solutions.

\subsubsection{All resources management}

The different HOUSEFUL circular solutions in the field of materials, water, waste and energy will compose the integrated system service that will be driven and promoted as a "Software as a Service (SaaS)", aiming at evaluating building circularity while offering different circular solutions as services to increase it for all stages of building life cycle. It will be created to support actors from the housing value chain to redesign their business model according to circular economy principles and it will be a user-friendly circularity tool for professionals but also for owners, dwellers and tenants will also be delivered to raise awareness of circular economy models.

A business plan of the HOUSEFUL model will be developed to provide circular services and products as new leasing and/or renting conditions to the housing sector. Special attention will be paid to the leasing and/or renting models for such physical solutions developed (as modular facades). The policy restrictions and safety checks will be reviewed to overcome major risks in the new commercialisation of solutions under new circular business models adapted to services.

The SaaS will offer two main features. The first is the a "circularity tool" to quantify the circularity level of residential buildings. Users will be able to work with data and calculation methods at two defined levels: (i) a free-access level with clearly defined and adapted key performance indicators such as water reuse $\left(\mathrm{m}^{3} / \mathrm{m}^{3} \cdot\right.$ day), total primary energy demand $\left(\mathrm{kWh} / \mathrm{m}^{2} \cdot \mathrm{yr}\right)$ and share of renewable energies (\%), etc.; and (ii) a pay-per-use interface with consumer specific oriented results, where different interventions will be suggested to enhance the circularity of the building and quantifying the effect of these interventions on the building. The circularity tool addresses the current information deficit by proposing a set of clearly defined and measurable indicators for the assessment of the environmental performance of residential buildings. The second feature is an interactive results sharing platform created with the primary aim of promoting the co-creation of new circular economy business opportunities by stakeholders in the housing sector. The platform will contain successful circular solutions and services demonstrated in the building, together with other successful experiences collected to promote the replication of these initiatives and facilitate the collaboration among stakeholders.

SaaS will underpin the housing value-chain and support the optimisation of its value proposition, clients, activities, partners, cost structures and revenue streams. Presently, some circular products do offer repositories for greener building design [2], or even new brand methodologies (such as Level(s) [3]), but none offer the combination of both. The SaaS service will not only evaluate the building circularity but offer explicit solutions to optimise it in a service mode based on performance/functionality rather than ownership.

\subsubsection{Materials}

Under HOUSEFUL, a solution to many problems affecting the construction industry (e.g. excessive waste and high costs [4]) will be provided in a digital format, focused on sharing data related to materials used in new and existing buildings, and their impacts on the environment. As part of this solution, Building Information Modelling (BIM) and the socalled "material passport" will be provided jointly as services driven to increase productivity and efficiency within the built environment, allowing for better decision making along the value chain from design to construction/refurbishment, operation, maintenance and demolition. 
The material passport will give an overview of products, components and materials used in the existing construction objects, updated in sequential years with financial valuations and able to provide advice on the architectural possibilities available to safeguard existing materials, and even re-incorporate their value into new building functions.

To better utilise local materials and thereby contributing to circularity by shortening the cycle, the HOUSEFUL intends to source over 50 types of building materials (existing or new commercial products) from secondary material platforms, databases and local producers, contributing to the debate on quality, origin and potential material reuse at local scale. The search will be focused on EU certified products, clearly contrasting technical and environmental specifications to allow for a complete material characterisation and the calculation of the building's potential impact along the building's overall value chain, namely manufacturing, design, construction, use and demolition phase. The results will then be included in a "Circular materials database" which will include, not only certified products (wood, steel, etc.), but also the cost and supply conditions associated or linked to these products. Some of these seemingly "more circular" products will be widely defined and detailed regarding potential uses, such as those contributing to the improvement of energy efficiency, or other such as certain paints, that may contribute to an improvement of indoor and outdoor air quality. The analysis of potential uses of certified building material is essential for the improvement of building circularity and this will furthermore facilitate the potential modelling of building characteristics and a provide successful quantification for impact analysis. Furthermore, the results can provide new circular business opportunities at local scale.

\subsubsection{Water}

Although water reuse is an established practise in some European countries, obtaining reclaimed water from the wastewater treatment plants, this practice is limited by the distance from application sites and the risk of industrial pollutants potentially present in centralised systems. Reclaimed water from wastewater treatment plants is usually recovered from tertiary treatments after the nutrients have been removed. However, considering that more than $70 \%$ of water reuse is intended for irrigation in agriculture, these beneficial nutrients should ideally remain in the water. In HOUSEFUL, rain-, grey- and blackwater will be treated in Nature-Based Solutions (NBS) to reclaim water for reuse after disinfection by commercial $\mathrm{UV} / \mathrm{O}_{3}$ to flush toilets, laundry or irrigation. The feasibility of the NBS technologies will be demonstrated within the project at building scale.

Green facades for the treatment of grey- and rainwater will be constructed at semi-pilot and pilot scale. The façade structures consist of more than $70 \%$ construction and demolition waste (CDW) and are furthermore designed for circular building with innate modularity and upcycling character. The outer layer will contain plants selected for rain- and greywater treatment and will also provide micro-climatic benefits, and plant/food production services.

An indoor vertical wetland ecosystem will purify the liquid fraction from un-segregated domestic wastewater. A vertical set-up combined with a horizontal subsurface flow (HSSF) was developed as a prototype for indoor use and has demonstrated functionality in a real environment with a greywater flow of up to $2 \mathrm{~m}^{3} /$ day. Offering such greywater treatment solutions to households or touristic facilities is greatly constrained by the need for a secondary plumbing system. Accordingly, HOUSEFUL plans to separate the liquid from the solid fraction of conventional wastewater and to then treat the liquid fraction in a HSSF, in an attempt to combine the lower levels of the treatment area with the production of edible plants. In addition to being aesthetically pleasing, the green wall supports air-purification and furthermore offers a home-level food production service. 
Similar vertical constructed wetland will be integrated into building adjacent wintergardens, designated for construction across all the building floors. The winter-gardens will function passively and autonomously and treat air channelled from inside the building, together with rainwater/treated wastewater.

The nutrient-rich wastewater will also be used in circular aquaponics and farming systems. Aquaponics will recirculate water from fish tanks through a vegetable culture bed. Nutrients from the fish waste feed the plants, and the plants filter the water to keep the fish healthy. The two main components of the system are the fish tanks and the grow beds with a small pump moving water between the two. The water passes through the root system before draining back into the fish tank. The plants take up the nutrients (fish waste) for their own growth and doing so, purify the water for the fish. The main benefit from a system like this is the ability to grow plants and breed fishes in one system with a relatively low energy consumption, fast growth rates and high yields. Eliminating the need for weeding and tilling of soil, plants are naturally fertilized and no wastewater run-off into the recirculating system.

A soap-bubble-insulated greenhouse (consisting of a foam generator filling a double walled greenhouse with soap bubbles) will provide for stable inner-greenhouse climate at night. The insulation can then be removed during day time to gather passive solar heat and allow light in for plant growth. Growing food in greenhouses during the winter may still not be economically viable due to the high cost of heating and the low thermal resistance of standard greenhouses, but the soap bubble-insulated greenhouse will allow for an extended operating season by increasing the thermal resistance of the greenhouse wall. In turn, this would allow cultivations with longer vegetation periods and also a longer harvesting season.

\subsubsection{Waste}

Waste prevention, re-use and similar measures could lead to net savings of $€ 600$ billion, or $8 \%$ of annual turnover, for businesses in the EU [5]. Within the HOUSEFUL project, we will further show that an efficient treatment and valorisation of blackwater and bio-waste could be used as an efficient resource for biogas production.

Blackwater and bio-waste will be treated together with a tailor-made compact AnMBR (Anaerobic Membrane Bioreactor) and dAD (Dry Anaerobic Digestion) reactors. The recovered biogas will be purified on site for storage during winter for further valorisation or used for direct electricity and heat production, reducing building energy needs. Resulting digestate will be treated and made available as fertilizer by the local community. Treated blackwater from AnMBR will be disinfected by UV hygienisation, for reuse.

AnMBR has never been tested and demonstrated for the treatment of wastewater and biowaste at building scale. In HOUSEFUL, optimal AnMBR configuration and membranes will be selected for efficient treatment of blackwater ( $\uparrow \mathrm{COD}$ ) and grinded BW ( $\uparrow \mathrm{COD}, \uparrow \mathrm{SS}$ ) mixed at optimal ratio at lab scale.

Compact, transportable and modular $\mathrm{dAD}$ aims to efficiently valorise bio-waste and manure for biogas production and compost at building scale. The system needs to work in a semi-continuous mode, being able to be automatically fed with almost dry waste. The technology will be designed according to energy needs of the building but also considering energy/compost needs of the neighbourhood which can provide bio-waste for renewable energy production and receive benefits from their engagement (i.e. compost). The system will be offered as a leasing service to promote the circular use and transition from property ownership to functionality (pay per use).

The AnMBR and dAD systems will allow a minimum recovery of over $95 \%$ food waste and $95 \%$ of organic matter from blackwater and wastewater for production of renewable energy from biogas and compost at home. Furthermore, biogas may be purified for storage 
and then used in winter times according to energy needs of buildings (or surrounding infrastructure in the neighbourhood as part of a potential collaborative economy), for CHP or heat generation and consumption by the own building $(2600 \mathrm{kWh} / \mathrm{y}$ renewable energy from biogas), or other co-creation possibilities. An exhaustive cleaning of biogas impurities $\left(\mathrm{CO}_{2}, \mathrm{H}_{2} \mathrm{~S}\right.$, dioxins) could allow its valorisation as natural gas-like fuel. Purified biogas can be stored and valorised for the production of renewable energy. HOUSEFUL will define the optimal energy valorisation options to cover energy needs of dwellers.

Several solutions for the stabilisation of bio-waste from anaerobic digestion systems will be tested at semi-pilot scale (laboratory environment) before demonstration and optimisation at building scale once connected to foreseen AnMBR or dAD technologies. In particular, an innovative compost cultivator prototype will be developed and optimised for large scale composting of fresh gardening wastes before mixing it with the dAD digestate.

Finally, an optimal waste management at the end of the building life cycle will allow analysis of maximum recovery and valorisation potential of existing building materials (i.e. envelope, facade, etc) to guarantee the best wastes management (reduction of $30 \% \mathrm{CDW}$ disposed in landfills).

\subsubsection{Energy}

Many EU projects have focused on reducing the energy demand and increasing the share of renewables in buildings with the aim to achieve NZEB. New business models are needed to be applied in the housing sector (i.e. pay per performance). HOUSEFUL will design energy efficient facades and roofs considering a circular approach, taking into account modular, prefabricated and off-site construction, design for disassembly, materials reuse, and recycling aspects will be considered.

An energy-saving service will be offered to reduce the non-renewable energy consumption in the usage phase of buildings and reducing billing costs to the lowest level. Energy improvement solutions such as envelope interventions (e.g. innovative facades, energy-efficient windows, etc.), solar thermal systems and shared photovoltaic systems will be proposed to reduce the energy demand of buildings and increase the share of renewable energies, contributing to the attainment of a near-Zero Energy Building (nZEB). The service includes an initial evaluation of the feasibility of proposed energy solutions as well as energy tips for dwellers to reduce energy costs, and the best renewable systems to be implemented, according to building characteristics, end-user profiles and the national regulations and energy markets backgrounds.

HOUSEFUL will guarantee co-creation based on performance rather than ownership, for energy systems (as solar thermal or photovoltaic) finally installed in each building (pay-perperformance business model) and monitoring of energy saving by active and passive measures adopted, from a material and energy valorisation points of view. Pay-perperformance business models will be promoted to be applied in the residential sector, where production is billed rather making the product available for ownership. By using this model, it is guaranteed that solar thermal and photovoltaic systems operate properly at least during the contract duration signed between the energy service company and the owner/neighbourhood community of the building. At the same time, these models proposed for leasing and rent require continuous monitoring of not only of the renewable energy production, but also of the energy consumptions of the end-users. Providing them the related information will help to reach the energy saving goals and thereby ensure the service under the agreed conditions. 


\section{EXPECTED HOUSEFUL IMPACT}

The HOUSEFUL solutions pursue specific objectives for a more circular housing sector: the design of new efficient processes and procedures for the construction/refurbishment and demolition phases, leading to net reduction in the use of resources, minimising the waste destined to landfills (reduction from current $40 \%$ to $10 \%$ in 10 years as realistic scenario) and selection/use of sustainable materials to improve the energy efficiency of buildings. The innovative technologies will be offered as new circular services for the production of treated water for internal reuse (i.e. for toilets recharge and irrigation), the generation of renewable energy at residential level of biogas for own consumption (i.e. CHP or heat) and the compost production for garden purposes for yourself and neighbours. In detail, the following technical objectives are foreseen: the recovery of more than $95 \%$ of food waste at home level by the successful separation of kitchen waste at source, grinding and valorisation as biogas; the recycling of over $90 \%$ of rain-, grey- and blackwater for production of reclaimed water and biogas; high quality biogas production from grinded bio-waste and blackwater and efficient valorisation (over 90\% conversion yield) as renewable heat and/or electricity at home level, able to endure the winter with its own heating system; high quality compost production from anaerobic digestate produced from the joint valorisation of bio-waste and blackwater; reducing the non-renewable primary energy consumption of buildings up to $50 \%$ related to the national regulations requirement by integrating the existing and proposed passive and active solutions, contributing to the achievement of near-Zero Energy Buildings (NZEB).

From the point of view of economic benefits, HOUSEFUL will provide new opportunities for (social) housing sector by offering new solutions with circularity principles having in mind the reuse of materials, resources and increasing the energy efficiency of buildings by passive and active planning. The uptake of recycled construction materials by other industries boosts industrial symbiosis at local/regional level. A preliminary evaluation of HOUSEFUL solutions predicts cost savings as follows: long-term cost savings of $10 \%$ (on average) of external energy and tap water costs through the use of treated wastewater and recovering of energy at building level; $80 \%$ (on average) costs saving of using treated wastewater and recovering energy at building level in relation to all external costs (including infrastructure cost); $70 \%$ (on average) savings on current fees for the treatment of wastewater and waste management of bio-waste.

From a point of view of social benefits, HOUSEFUL will create different circular economy business models for EU markets for waste, water, energy and material flows and will be designed to promote leasing, customer services and capacity building services. Since the responsibility of the service/product/technology lies with the provider and not with the costumers, the quality of the services is higher and much more in demand [6].

In terms of environmental benefits, HOUSEFUL will tackle the energy efficiency of existing and newly constructed buildings in two different ways: by using a $\mu \mathrm{CHP}$ to provide end-users with heat and electricity from wastewater and bio-waste and by planning and designing the use of more energy efficient products and services in the preventive, corrective and replacement phases of selected residential buildings. With these solutions, we estimate a reduction of up to $60 \%$ of $\mathrm{CO}_{2}$ emissions, contributing to the efforts to limit the global temperature rise to $1.5^{\circ} \mathrm{C}$, as provided for in the COP21 Paris Agreement.

The optimal use of the water, bio-waste and materials cycles within the building will reduce by up to $40 \%$ waste ending up in landfill, enabling recovery of up to $95 \%$ of food waste and the recycling of over $90 \%$ of WW (grey- and blackwater) for water reuse (e.g. irrigation, toilets), improving the energy efficiency of buildings of up to $30 \%$. The $40 \%$ reduction in waste disposed of landfills will significantly reduce the risk of hazardous 
substance released into the environment (e. bituminous mixtures, solvents, paints) that are strongly harmful to the environment and human health.

\section{REFERENCES}

[1] Stuchtey, M., Enkvist, P.A. \& Zumwinkel, K., A Good Disruption: Redefining Growth in the Twenty-First Century, Bloomsbury Business, 2016.

[2] Cradle to Cradle inspired Buildings, EPEA Internationale Umweltforschung $\mathrm{GmbH}$. www.epea.com/c2c-sectors/buildings/.

[3] Dodd, N., Cordella, M., Traverso, M., Donatello, S., Level(s): A common EU framework of core sustainability indicators for office and residential buildings. European Commission Joint Research Centre Directorate B, Growth and Innovation Unit 5, Circular Economy and Industrial Leadership, pp. 5-20, 2017.

[4] Molenbroek, E., Cuijpers, M. \& Blok, K., Economic Benefits of the EU Ecodesign Directive. Improving European Economies, ECOFYS, 2012.

[5] Circular Economy Package, Questions and Answers. http://europa.eu/rapid/pressrelease_MEMO-15-6204_en.htm.

[6] Wijkman, A. \& Skanberg K., Club of Rome. The Circular Economy and Benefits for Society, Club of Rome, 2015. 